Check for updates

New York

Cite this as: $B M J$ 2021;373:n1640 http://dx.doi.org/10.1136/bmj.n1640 Published: 25 June 2021

\title{
Covid-19: US doctors suggest new ways to target vaccine hesitancy
}

\section{Janice Hopkins Tanne}

President Biden admitted on 22 June that the US would miss the target of vaccinating $70 \%$ of adults by the 4 July holiday, but he continued his push to increase the vaccination rate. Experts at Johns Hopkins Bloomberg School of Public Health suggested ways to vaccinate people who were hesitant, such as allowing family groups to be vaccinated at the same time rather than by age.

Although covid-19 is killing more people worldwide this year than in 2020, vaccine hesitancy in the US means that fewer people are receiving the vaccine every day-only about 300 ooo per day compared with nearly 2 million a day in early April. ${ }^{1}$ Nearly $66 \%$ of people aged 18 or older-over 178 million-have received at least one dose of the vaccine, including more than 151 million people who are fully vaccinated, according to the Centers for Disease Control and Prevention. Of people over 65 years old, $88 \%$ have received at least one dose of the vaccine, compared with only $66 \%$ of those aged 18 to $64 .^{2}$

The proportion of people who have received at least one dose of the vaccine varied from $85 \%$ in the north eastern state of Vermont to $46 \%$ in the southern state of Mississippi. ${ }^{2}$ Infections have risen in the past two weeks by $63 \%$ in Oklahoma, $51 \%$ in Arkansas and Missouri, 46\% in Alaska, 26\% in Nevada, 22\% in Arizona, and $18 \%$ in Utah. Those infected are more likely to be younger people in rural areas. Clusters have occurred at several universities.

Lisa Cooper, director of the Johns Hopkins Center for Health Equity and professor of medicine, said at a press briefing, "Although we have a high proportion of our population vaccinated, we still have pockets of our population including ethnic minorities, particularly African Americans, and people across geographic regions who remain unvaccinated due to concerns around either the vaccine itself or around access and distribution issues.”

Distribution of vaccine was a major concern, said Rupali Limaye, director of behavioural and implementation science at the International Vaccine Access Center of Johns Hopkins Bloomberg School of Public Health. Federal and state governments need to ensure innovative distribution channels "so you are meeting people where they are in communities." People report difficulty in making vaccine appointments by computer and in getting to clinics, and they don't trust the vaccine because of misinformation on social media, she said.

African Americans and people who are conservative politically are less likely to accept vaccinations, Limaye said. Cooper said that discussion of a possible laboratory leak of the virus has increased mistrust in medicine and science.

Vaccine hesitancy can be tackled by having trusted community leaders, business leaders, family doctors, and (in African American communities) the clergy provide correct vaccine information. Limaye said that would counteract the widespread misinformation on social media. Incentives such as free donuts or a chance to win a college scholarship have been used in some locations. Pop-up clinics, distribution through employers, and allowing people time off to get vaccinated would all help.

She also suggested improvements in access. Instead of vaccines being administered by age groups, as it was in the beginning, vaccine centres could allow family groups to be vaccinated together. This would reduce the need for complicated scheduling for first and second doses for family members of different ages.

Cooper said that the pandemic has shown how social inequalities increase health costs, led to loss of productivity, civic unrest, and human suffering, as well as to pandemic spread and lockdowns: "We've seen how interconnected we all are.”

$1 \quad$ Miller Z. Falling short: Why the White House will miss its vax target. Associated Press, June 24, 2021. https://apnews.com/article/why-the-bidenwhite-house-will-miss-covid-vaccination-targete3985c9958b579a44a168cb6e0649349

2 Coronavirus in the US. Latest map and case count. New York Times, June 24, 2021. https://www.nytimes.com/interactive/2021/us/covid-cases.htm

This article is made freely available for use in accordance with BMJ's website terms and conditions for the duration of the covid-19 pandemic or until otherwise determined by BMJ. You may use, download and print the article for any lawful, non-commercial purpose (including text and data mining) provided that all copyright notices and trade marks are retained. 